\title{
Posterior kortikal atrofi
}

BAKGRUNN Posterior kortikal atrofi er en nevrodegenerativ tilstand med atrofi av bakre deler av hjernebarken, inkludert synscortex og deler av parietal- og temporalcortex. Den debuterer tidlig, i 50-60-årsalderen, med uspesifikke synsproblemer som ofte feiltolkes som oftalmologiske, hvilket kan forsinke diagnosen. Hensikten med denne artikkelen er å presentere oppdatert kunnskap om symptomer, diagnostikk og behandling av tilstanden.

KUNNSKAPSGRUNNLAG Oversikten er basert på et utvalg relevante artikler fra PubMed og på forfatternes egne erfaringer med pasientgruppen.

RESULTATER Posterior kortikal atrofi gir gradvis økende problemer med lesing, avstandsbedømmelse og evnen til å oppfatte sammensatte bilder. Undersøkelse av høyere visuelle funksjoner, nevropsykologisk testing og nevroradiologiske undersøkelser bidrar til korrekt diagnose. I tidlig fase har pasienten ikke hukommelses- og innsiktsproblemer, men kognitiv svikt og demens kan komme etter hvert. Det er uavklart om tilstanden er en variant av Alzheimers sykdom eller om den er en egen sykdomsentitet. Det finnes ingen etablert behandling, men praktiske tiltak som støttekontakt, telefon med store taster, PC med talegjenkjennende programvare og lydbøker kan være nyttig.

FORTOLKNING Den behandlingen som finnes i dag, har meget begrenset effekt på selve sykdommen. Likevel er det viktig å identifisere og diagnostisere tilstanden i en tidlig fase for å kunne tilby pasienten praktisk hjelp i dagliglivet.

Posterior kortikal atrofi (posterior cortical atrophy, PCA) er et syndrom som medfører synsproblemer på grunn av nevrodegenerasjon i oksipitale, parietale og oksipito-temporale områder, dvs. de bakre deler av hjernebarken (1). I tidlig fase er symptomene lite uttalte og består av lesevansker og visuospatiale problemer. Senere kan syndromet utvikle seg til en mer omfattende demenstilstand.

Diagnosen stilles på grunnlag av anamnese, undersøkelse av høyere visuelle funksjoner og nevroradiologiske undersøkelser. Hensikten med denne artikkelen er å presentere oppdatert kunnskap om posterior kortikal atrofi for å bidra til bedre diagnostikk og håndtering av tilstanden.

\section{Kunnskapsgrunnlag}

Artikkelen er basert på en gjennomgang av litteratur etter søk i PubMed frem til 30.4. 2014. Vi brukte søkeordene «posterior cortical atrophy», som identifiserte 866 artikler, «visual dementia AND brain atrophy», som identifiserte 479 artikler, og «dementia AND visual problems», som identifiserte 197 artikler.

Ut fra sammendragene ble det valgt 30 original- og oversiktsartikler som ble vurdert som representative for publikasjoner om tilstanden fra perioden 1985-2014. Originalartiklene som ble valgt, var de som først rapporterte vesentlige funn, mens oversiktsartiklene som ble valgt, kom fra medisinske miljøer med lang erfaring i diagnostikk og behandling av posterior kortikal atrofi.

\section{Forekomst}

Prevalensen av posterior kortikal atrofi er ikke kjent. Tilstanden regnes som sjelden, men den er sannsynligvis underrapportert (2). Debutsymptomene starter ofte i 50-60årsalderen (3).

Menn og kvinner rammes antakelig like ofte $(3,4)$, selv om det i enkelte artikler antydes hyppigere forekomst hos kvinner (5, 6). Gjennomsnittlig tid mellom debutsymptomer og rett diagnose er omtrent fire år. De fleste søker først hjelp hos øyelege før de kommer til nevrolog (6).

\section{Kliniske funn}

Tidlig stadium

Det første symptomet er vanligvis problemer med å lese. Pasienten har vansker med å flytte blikket fra én linje til den neste og har også vansker med å forstå innholdet i en tekst. Det er verdt å merke seg at pasienter med posterior kortikal atrofi har mindre vansker med å lese tekst med små bokstaver enn med store. Dette gjelder ikke utelukkende lange og vanskelige ord, men også korte ord, enkeltbokstaver og tall. Fenomenet kalles «innsnevret funksjonelt synsfelt» og innebærer at man ikke klarer å holde oversikten over hele synsfeltet $(7,8)$.

Pasientene har også vansker med å forstå hele synsinntrykket på grunn av «visual crowding», som betyr at nabostimuli maskerer eller «trenger seg innpå» det objektet man fokuserer på (9-11). Noen får vansker med å gjenkjenne eller lokalisere objekter. Andre rapporterer om feilbedømming av avstand og vansker med å gå i trapper som

\author{
Volker Moræus Solyga \\ volsol@so-hf.no \\ Nevrologisk avdeling \\ Sykehuset Østfold Fredrikstad
}

\section{Elin Western}

Psykosomatisk avdeling

Oslo universitetssykehus, Rikshospitalet

Hanne Solheim

Nukleærmedisinsk avdeling

Oslo universitetssykehus, Radiumhospitalet

\section{Bjørnar Hassel}

Nevrologisk avdeling

Oslo universitetssykehus, Rikshospitalet og

Forsvarets forskningsinstitutt

Kjeller

Emilia Kerty

Nevrologisk avdeling

Oslo universitetssykehus, Rikshospitalet

og

Det medisinske fakultet

Universitetet i Oslo

\section{HOVEDBUDSKAP}

Posterior kortikal atrofi (PCA) er en nevrodegenerativ sykdom i de bakre delene av hjernebarken

Den begynner oftest i 50-60-årene, med lesevansker, problemer med avstandsbedømmelse og svekket evne til å oppfatte sammensatte bilder

Diagnosen er basert på symptomene, nevropsykologiske undersøkelser og bildediagnostikk, hovedsakelig MR- og PETundersøkelse av hjernen

Foreløpig finnes det ingen etablert behandling, men praktiske hjelpetiltak kan lette pasientens hverdag 


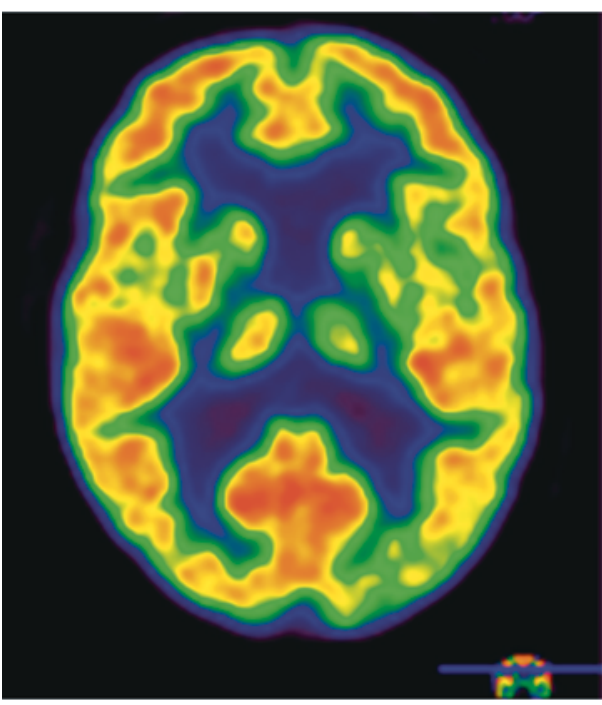

Figur 1 Positronemisjonstomografi (PET) med en radioaktivt merket glukoseanalog ( ${ }^{18} \mathrm{FDG}$ ) er en funksjonell nukleærmedisinsk metode som viser glukoseopptaket i hjernen. Glukoseopptaket reflekterer nervecelleaktiviteten. Rød farge representerer høyt glukoseopptak og høy nervecelleaktivitet, blå farge lav aktivitet. a) Normal PET-undersøkelse. b) Ved posterior kortikal atrofi finner man nedsatt metabolsk aktivitet i bakre hjerneområder, mest høyre side (piler)

initiale symptomer (12), eller at de bommer på, eller kolliderer med, objekter (13).

Redusert oppmerksomhet mot den ene siden av synsfeltet (visuell neglekt) forekommer regelmessig og gir økt risiko for å falle (14). Mange pasienter opplever vansker med bilkjøring og parkering, dels grunnet dårlig avstandsbedømmelse, dels manglende evne til å lokalisere objekter i rommet. Mange rapporterer om lysømfintlighet, hvilket kan mistolkes som migrene (2).

\section{Senere stadium}

I senere stadier av sykdommen kan man hos de fleste pasienter påvise homonym hemianopsi, kvadrantanopsi eller bilateral innskrenkning av synsfeltet ved hjelp av synsfelttesting $(15,16)$. Venstresidige, homonyme hemifeltdefekter er vanligst. Neglekt, og det at pasienten bare oppfatter visuelle stimuli i den ene halvdelen av synsfeltet når to stimuli presenteres samtidig i hvert synshalvfelt (visuell ekstinksjon), kan være vanskelig å påvise ved tidlig posterior kortikal atrofi på grunn av ledsagende manglende evne til gjenkjennelse/forståelse av visuelle inntrykk (visuell agnosi), til tross for bevart synsskarphet. I senere stadier av sykdommen kan neglekt og visuell ekstinksjon være mer fremtredende $(1,6,14,17)$.

Visuell agnosi skyldes manglende kortikal viderebehandling av primærpersepsjonen av et objekt slik at objektet ikke gir mening for pasienten. Simultanagnosi, som også er vanlig ved posterior kortikal atrofi, er manglende evne til å oppfatte mer enn ett objekt om gangen og forstå helheten i et komplekst

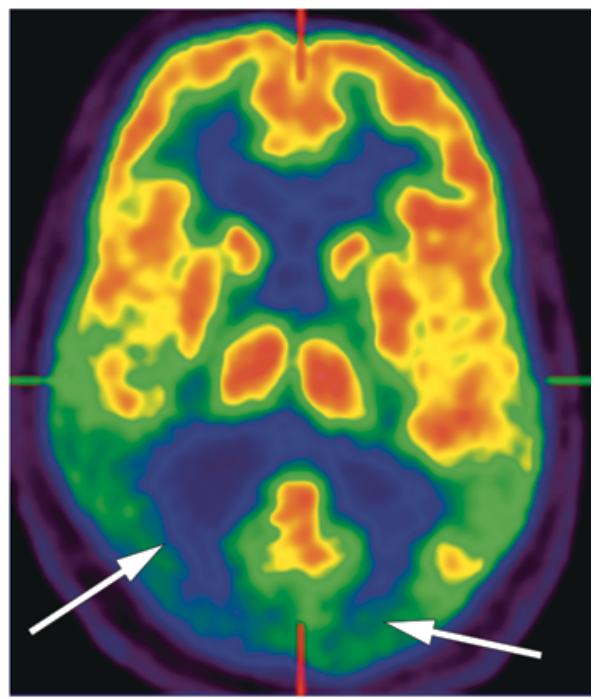

RAMME 1

Foreslåtte diagnostiske kriterier for posterior kortikal atrofi (6)

\section{Hovedkriterier (må være til stede):}

Snikende start og langsom progrediering Synsproblemer uten primære patologiske funn i øynene, hjerneslag eller hjernetumor som kan forklare symptomene

Bevart hukommelse, selvinnsikt og verbal flyt

Ett eller flere av følgende symptomer: visuell agnosi, simultanagnosi, optisk ataksi, okulomotorisk apraksi, synsfeltdefekt, desorientering i omgivelsene, og ethvert element av Gerstmanns syndrom lakalkuli, fingeragnosi og høyre-venstre-forvirringl

\section{Tilleggskriterier som støtter diagnosen:} Aleksi, apraksi, prosopagnosi

Presenil start

Nevropsykologiske utfall som indikerer parietal og/eller oksipital dysfunksjon Fokal eller asymmetrisk atrofi i parietale/ oksipitale områder ved nevroradiologisk undersøkelse

Fokal eller asymmetrisk hypoperfusjon/ hypometabolisme i parietale/oksipitale områder ved ${ }^{18}$ FDG-PET- eller SPECTundersøkelse

Balints syndrom, som blant annet består av simultanagnosi (se forklaring over), sviktende evne til å utføre presise bevegelser i rommet under visuell kontroll (optisk ataksi) og usikkerhet med hensyn til å rette blikket mot nye visuelle stimuli (okulomotorisk apraksi), kan påvises hos de fleste pasienter senere i sykdommen. Symptomer på Gerstmanns syndrom, som vansker med enkle regneoppgaver (akalkuli), vansker med å benevne fingrene (fingeragnosi) og høyrevenstre-forvirring, kan også forekomme i senere stadier (17).

Visuelle hallusinasjoner er blitt rapportert hos en knapp firedel av pasientene $(6,12)$. Disse opptrer vanligvis som spontane, residiverende synsopplevelser og kan forekomme både i tidlig og sent stadium av sykdommen. Ikke sjelden forteller pasienter om fargede objekter som henger igjen etter at de reelle objektene ikke lenger befinner seg $i$ synsfeltet (after image).

De foreslåtte internasjonale diagnostiske kriterier for posterior kortikal atrofi omfatter progredierende synsproblemer med snikende start og fravær av primære patologiske øyefunn, hjerneslag eller hjernesvulst som kan forklare symptomene (6). Mer detaljerte diagnostiske kriterier vises i ramme 1 (6).

\section{Utredning}

De fleste pasienter med posterior kortikal atrofi oppsøker først øyelege, før de blir henvist videre til nevrolog. Okulære forand- ringer ved klinisk undersøkelse er uvanlig $(3,13)$. Det kan imidlertid være vanskelig å bestemme visus på grunn av defekt fikseringsevne (13). I tillegg til en grundig anamnese bør det gjøres fullstendig nevrologisk undersøkelse. Ved mistanke om posterior kortikal atrofi bør også nevropsykologisk undersøkelse utføres.

Mer enn $90 \%$ av pasientene har funn i spinalvæsken som ved Alzheimers sykdom, med økt konsentrasjon av tauproteinet (t-tau) og fosforylert tau (p-tau) samt nedsatt konsentrasjon av betaamyloidpeptidet $\left(\mathrm{A} \beta_{42}\right)$ (19).

Genvarianten apolipoprotein E4 (apoE4) er assosiert med økt risiko for Alzheimers sykdom. Det er observert økt frekvens av apoE4 hos pasienter med posterior kortikal atrofi i noen store studier $(18,20)$, mens noen mindre studier har vist lavere forekomst av apoE4-allelet (21). Cerebral MRundersøkelse kan være normal i tidlig fase. Senere i forløpet kan man se kortikal atrofi parieto-oksipitalt, som regel mer uttalt $\mathrm{i}$ høyre enn i venstre hemisfære (22). Hvis MR-funn ikke gir grunnlag for diagnosen, kan positronemisjonstomografi (PET) med radioaktiv glukose-analog $\left({ }^{18} \mathrm{FDG}\right)$ vise nedsatt metabolisme i bakre deler av de 


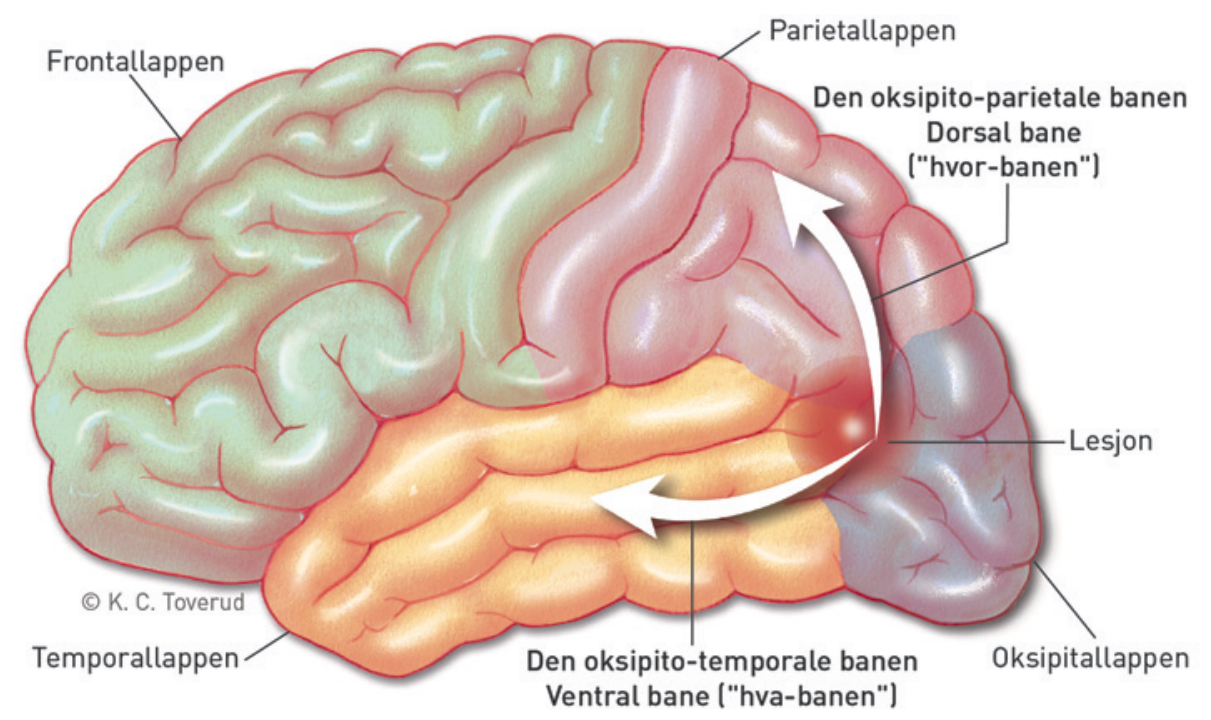

Figur 2 Den oksipito-parietale banen formidler spatial informasjon (dorsal bane, også kjent som «hvor-banen»). Den oksipito-temporale banen formidler informasjon om objektidentifikasjon (ventral bane, også kjent som «hva-banen»)

cerebrale hemisfærer (13) (fig 1). Hypometabolismen er gjerne mest uttalt i høyre hemisfære.

I en sammenlikning med friske kontrollpersoner fant Nestor og medarbeidere at det ved posterior kortikal atrofi også var frontal hypometabolisme dorsolateralt bilateralt, svarende til de frontale øyefeltene. Dette funnet ble tolket som uttrykk for manglende input fra oksipito-parietale områder til frontalcortex (13). De frontale øyefeltene er essensielle for raske voluntære øyebevegelser, og de mottar viktig input fra de visuelle assosiasjonsområdene. Forstyrrelse av denne forbindelsen er én mulig årsak til okulomotorisk apraksi hos pasienter med posterior kortikal atrofi (13).

Enfotonemisjonstomografi (SPECT) viser hjernens blodgjennomstrømming og påviser i prinsipp de samme utfallene som ${ }^{18}$ FDGPET, siden blodforsyning og glukosemetabolisme er nær knyttet til hverandre. Vår egen erfaring med denne pasientgruppen taler for å bruke FDG-PET hvis metoden er tilgjengelig, fordi den fremstiller det typiske metabolismemønsteret ved posterior kortikal atrofi tydeligere enn SPECT-metoden gjør.

\section{Nevropsykologiske funn}

Pasienten har relativt godt bevart hukommelse, verbal flyt og selvinnsikt. I tillegg kan det være ett eller flere tegn på Balints og/eller Gerstmanns syndrom, slik det er beskrevet over. Undersøkelse av høyere visuelle kognitive funksjoner med spesifikke visuospatiale eller visuoperseptuelle tester kan avsløre nevropsykologiske utfall. Noen slike tester er figurkopiering, som er en del av MMSEtesten (Mini Mental Status Examination), og klokketegningstesten, mens linjedelingstesten påviser visuell neglekt (14).

En studie viste at pasienter med posterior kortikal atrofi tidlig hadde fremtredende visuospatial svikt og at de senere utviklet visuell agnosi (17). Hukommelses- og frontallappsfunksjonene var imidlertid relativt intakte gjennom sykdomsforløpet. I de fleste nevropsykologiske studier av pasienter med posterior kortikal atrofi har man kun lagt vekt på kartlegging av visuospatiale ferdigheter, mens andre kognitive funksjoner som blant annet eksekutivfunksjoner ikke er blitt like grundig undersøkt. For å kunne definere en distinkt nevropsykologisk profil hos pasientene må man benytte seg av et bredt spekter av nevropsykologiske tester (23).

\section{Patologiske funn}

Det finnes ikke mange nevropatologiske studier av pasienter med posterior kortikal atrofi. De fleste rapporterer amyloide plakk og nevrofibrillære floker, slik man ser ved Alzheimers sykdom, men hovedsakelig i bakre hjerneområder $(4,6)$. Enkelte kasuistikker med kortikobasal degenerasjon, lewylegemedemens, subkortikal gliose eller prionsykdommer, som fatal familiær insomni og Creutzfeldt-Jakobs sykdom, er også blitt beskrevet (4, 6, 24).

Midthjerne og basalganglier er affisert hos dem som har hallusinasjoner, og dette kan muligens forklare hvorfor disse pasientene $(>75 \%)$ i tillegg har parkinsonistiske symptomer (12).

Forskjellige typer visuell informasjon bearbeides $i$ et samarbeid mellom forskjellige deler av hjernebarken. Den oksipitoparietale banen formidler spatial informasjon (den dorsale banen, også kjent som «hvor-banen»), mens den oksipito-temporale banen formidler objektidentifikasjon (den ventrale banen, også kjent som «hvabanen») (25) (fig 2). Skade på de oksipitoparietale banene fører til Balints syndrom, apraksi og partielt eller komplett Gerstmanns syndrom $(1,6,26)$. Skade på de oksipito-temporale banene fører til visuell agnosi, aleksi og prosopagnosi $(6,26)$.

Basert på enkelttilfeller har man diskutert om det finnes isolerte former med enten ventralbane- eller dorsalbaneaffeksjon ved posterior kortikal atrofi. Senere undersøkelser konkluderer med at det heller dreier seg om forskjellige utviklingstrinn av tilstanden (27).

\section{Posterior kortikal atrofi og Alzheimers sykdom}

I en metaanalyse fant Alves og medarbeidere (22) at pasienter med posterior kortikal atrofi hadde signifikant større vansker med visuopersepsjon, visuospatiale oppgaver og visuospatial korttidshukommelse enn pasienter med Alzheimers sykdom. Klinisk skiller altså de førstnevnte seg ut ved at man først og fremst ser typiske synsproblemer og overveiende oksipito-parietale defekter, mens hukommelsen er relativt godt bevart, særlig i den tidlige fasen av sykdommen $(17,18,27)$. Selvinnsikten er gjerne også bevart, og dette fører ofte til angst og depresjon ved posterior kortikal atrofi, mens atferdsendringer er sjeldent $(1,3)$. Både ved Alzheimers sykdom og posterior kortikal atrofi er frontallappsfunksjonene relativt godt bevart langt ut i sykdomsforløpet (22).

Det har vært foreslått at posterior kortikal atrofi starter som et distinkt klinisk syndrom (28). Denne tanken støttes av at omtrent $5 \%$ 
av alle pasienter med Alzheimers sykdom debuterer med symptomer på posterior kortikal atrofi (29) og at opptil $80 \%$ av pasientene med posterior kortikal atrofi har patologiske funn som ved Alzheimers sykdom ved autopsi $(4,6)$.

Men i en metaanalyse basert på 11 studier av 204 pasienter med posterior kortikal atrofi og 184 pasienter med Alzheimers sykdom fant man at hjerneatrofien ved førstnevnte tilstand hovedsakelig er lokalisert i høyre oksipitallapp, mens atrofien ved Alzheimers sykdom er mest uttalt i venstre hippocampus og parahippokampalområde (22). Posterior kortikal atrofi kan altså forstås som en variant av Alzheimers sykdom som begynner i de bakre deler av hjernebarken for så å bre seg fremover, men også som en spesifikk tilstand som rammer bakre hjernebarkområder, med histopatologiske funn som ved Alzheimers sykdom.

\section{Behandling}

Selv om det ikke finnes noen helbredende behandling for posterior kortikal atrofi, bør klinikere alltid forsøke å stille diagnosen tidlig - for å redusere risikoen for å misforstå tilstanden som et okulært problem, noe som kan føre til feilbehandling. Det er også viktig å stille diagnosen tidlig for å motvirke at pasientene hemmes unødvendig av sitt visuelle handikap og reduserte evne til å orientere seg i rommet. Slike symptomer kan føre til depresjon og sosial isolasjon.

Flere tiltak kan bedre livskvaliteten og hverdagsfunksjonen til pasientene. For eksempel kan støttekontakt, personlig assistent og diverse utstyr som primært er tiltenkt synshemmede (telefon med enkle taster, PC med talegjenkjennende programvare, lydbøker, lydklokke og tilpasset belysning i hjemmet) lette hverdagen.

Henvisning til synspedagog kan vurderes. Bruk av lese-TV med større avstand mellom bokstavene kan motvirke «visual crowding» og dermed gi økt leseferdighet. Enkle tiltak som kontrastfarger ved trapper kan redusere risikoen for fall for pasienter med dårlig avstandsbedømmelse.

Acetylkolinesterasehemmere har vist seg gunstig i enkelttilfeller (30), men har ingen etablert plass $\mathrm{i}$ behandlingen av posterior kortikal atrofi. De fleste pasientene har sluttet å kjøre bil før diagnosen er stilt, men det er nødvendig med kjøreforbud og melding til fylkesmannen.

\section{Volker Moræus Solyga (f. 1973)}

er spesialist i nevrologi og avdelingssjef

Forfatter har fylt ut ICMJE-skjemaet og oppgir ingen interessekonflikter.

\section{Elin Western (f. 1983)}

er psykolog under spesialisering i klinisk nevropsykologi.

Forfatter har fylt ut ICMJE-skjemaet og oppgir ingen interessekonflikter.

\section{Hanne Solheim (f. 1965)}

er spesialist i nukleærmedisin, med spesialkompetanse på PET-CT. Hun er lege i spesialisering i radiologi ved Avdeling for radiologi og nukleærmedisin, Oslo universitetssykehus, Radiumhospitalet.

Forfatter har fylt ut ICMJE-skjemaet og oppgir ingen interessekonflikter.

\section{Bjørnar Hassel (f. 1959)}

er spesialist i nevrologi, overlege og seniorforsker.

Forfatter har fylt ut ICMJE-skjemaet og oppgir ingen interessekonflikter.

\section{Emilia Kerty (f. 1948)}

er spesialist i øyesykdommer og i nevrologi, med spesialfelt nevrooftalmologi, overlege og professor II.

Forfatter har fylt ut ICMJE-skjemaet og oppgir ingen interessekonflikter.

\section{Litteratur}

1. Benson DF. Davis RJ, Snyder BD. Posterior cortical atrophy. Arch Neurol 1988; 45: 789-93.

2. Crutch SJ, Lehmann M, Schott JM et al. Posterior cortical atrophy. Lancet Neurol 2012; 11: 170-8.

3. Mendez MF, Ghajarania M. Perryman KM. Posterior cortical atrophy: clinical characteristics and differences compared to Alzheimer's disease. Dement Geriatr Cogn Disord 2002; 14: 33-40.

4. Renner JA, Burns JM, Hou CE et al. Progressive posterior cortical dysfunction: a clinicopathologic series. Neurology 2004; 63: 1175-80.

5. Kas A, de Souza LC, Samri D et al. Neural correlates of cognitive impairment in posterior cortical atrophy. Brain 2011; 134: 1464-78.

6. Tang-Wai DF, Graff-Radford NR, Boeve BF et al. Clinical, genetic, and neuropathologic characteris tics of posterior cortical atrophy. Neurology 2004 63: $1168-74$.

7. Russell C, Malhotra P. Deidda C et al. Dynamic attentional modulation of vision across space and time after right hemisphere stroke and in ageing. Cortex 2013; 49: 1874-83.

8. Russell C, Malhotra P. Husain M. Attention modulates the visual field in healthy observers and parietal patients. Neuroreport 2004; 15: 2189-93.

9. Pelli DG, Palomares M, Majaj NJ. Crowding is unlike ordinary masking: distinguishing feature integration from detection. J Vis 2004; 4: 1136-69.

10. Crutch SJ, Warrington EK. Foveal crowding in posterior cortical atrophy: a specific early-visualprocessing deficit affecting word reading. Cogn Neuropsychol 2007: 24: 843-66.

11. Crutch SJ, Warrington EK. The relationship between visual crowding and letter confusability: towards an understanding of dyslexia in posterior cortical atrophy. Cogn Neuropsychol 2009; 26 : 471-98.

12. Josephs KA, Whitwell JL, Boeve BF et al. Visual hallucinations in posterior cortical atrophy. Arch Neurol 2006; 63: 1427-32

13. Nestor PJ, Caine D, Fryer TD et al. The topography of metabolic deficits in posterior cortical atrophy (the visual variant of Alzheimer's disease) with FDG-PET. J Neurol Neurosurg Psychiatry 2003: 74: 1521-9.

14. Andrade K, Samri D, Sarazin M et al. Visual neglect in posterior cortical atrophy. BMC Neurol 2010; 10: 68

15. Pelak VS, Smyth SF, Boyer PJ et al. Computerized visual field defects in posterior cortical atrophy. Neurology 2011; 77: 2119-22.

16. Reñé R, Muñoz S, Campdelacreu J et al. Complex visual manifestations of posterior cortical atrophy. J Neuroophthalmol 2012; 32: 307-12

17. McMonagle P, Deering F, Berliner Y et al. The cog nitive profile of posterior cortical atrophy. Neurology 2006; 66: 331-8

18. Migliaccio R, Agosta F, Rascovsky K et al. Clinical syndromes associated with posterior atrophy: early age at onset AD spectrum. Neurology 2009; 73: $1571-8$

19. Seguin J, Formaglio M, Perret-Liaudet A et al. CSF biomarkers in posterior cortical atrophy. Neurology 2011; 76: 1782-8.

20. Carrasquillo MM, Khan Q, Murray ME et al. Lateonset Alzheimer disease genetic variants in posterior cortical atrophy and posterior AD. Neurology 2014: 82: 1455-62.

21. Schott JM, Ridha BH, Crutch SJ et al. Apolipoprotein e genotype modifies the phenotype of Alzheimer disease. Arch Neurol 2006; 63: 155-6.

22. Alves J, Soares JM, Sampaio A et al. Posterior cortical atrophy and Alzheimer's disease: a metaanalytic review of neuropsychological and brain morphometry studies. Brain Imaging Behav 2013 7: 353-61

23. Aresi A, Giovagnoli AR. The role of neuropsychology in distinguishing the posterior cortical atrophy syndrome and Alzheimer's disease. J Alzheimers Dis 2009; 18: 65-70

24. Victoroff J, Ross GW, Benson DF et al. Posterior cortical atrophy Neuropathologic correlations. Arch Neurol 1994; 51: 269-74.

25. Ungerleider LG, Haxby JV. 'What' and 'where' in the human brain. Curr Opin Neurobiol 1994; 4: 157-65.

26. Tang-Wai D, Mapstone M. What are we seeing? Is posterior cortical atrophy just Alzheimer disease? Neurology 2006; 66: 300-1.

27. Lehmann M, Barnes J, Ridgway GR et al. Basic visual function and cortical thickness patterns in posterior cortical atrophy. Cereb Cortex 2011; 21: $2122-32$

28. Lehmann M, Barnes J, Ridgway GR et al. Global gray matter changes in posterior cortical atrophy: a serial imaging study. Alzheimers Dement 2012 8: $502-12$

29. Snowden JS, Stopford CL, Julien CL et al. Cognitive phenotypes in Alzheimer's disease and genetic risk. Cortex 2007: 43: 835-45.

30. Kim E, Lee Y, Lee J et al. A case with cholinesterase inhibitor responsive asymmetric posterior cortical atrophy. Clin Neurol Neurosurg 2005: 108: 97-101.

Mottatt 15.9. 2014, første revisjon innsendt 8.3. 2015, godkjent 7.4. 2015. Redaktør: Tor Rosness. 